COMUNICAÇÃO CIENTÍFICA

\title{
REAÇÃO DE GERMOPLASMA DE GIRASSOL À MANCHA DE SEPTORIA CAUSADA POR SEPTORIA HELIANTHI
}

\author{
L.N. Marques ${ }^{1}$, G. Lenz ${ }^{1}$, I.F.D. Costa ${ }^{1}$, J.V.C. Guedes ${ }^{1}$, M. Bigolin' ${ }^{1}$, A.C.B. Oliveira ${ }^{2}$ \\ ${ }^{1}$ Universidade Federal de Santa Maria, Centro de Ciências Rurais, Departamento de Defesa Fitossanitária, \\ Clínica Fitossanitária, Av. Roraima, 1000, CEP 97105-900, Santa Maria, RS, Brasil. E-mail: giuvanlenz@ \\ gmail.com
}

\section{RESUMO}

Com o objetivo de avaliar a reação de germoplasma de girassol ao fungo Septoria helianthi, foi realizado um estudo sob condições de campo em uma área experimental na Universidade Federal de Santa Maria, Santa Maria, RS, no ano de 2008. O ensaio foi constituído por vinte e quatro genótipos de girassol semeados manualmente nas parcelas, em delineamento de blocos ao acaso com quatro repetições. Foi realizado o cálculo da taxa de progresso da doença e da área abaixo da curva de progresso da doença (AACPD) baseado nos dados de severidade nos terços inferior, médio e superior das plantas. As cultivares mais resistentes, isto é, que apresentaram menor AACPD foram PARAÍSO 33 seguida por HLE 16, HLE 17, EXP 1452 CL, V 20041 e SRM 840.

PALAVRAS-CHAVE: Mancha foliar, resistência genética, Helianthus annuus.

\section{ABSTRACT}

REACTIONOFSUNFLOWERGERMPLASMTOSEPTORIALEAFSPOTCAUSEDBY SEPTORIA HELIANTHI. With the objective of evaluating the reaction of sunflower germplasm in relation to the resistance of Septoria helianthi, a study was conducted under field conditions in an experimental area at the Federal University of Santa Maria, Santa Maria, state of Rio Grande do Sul, Brazil, in 2008. The experiment involved 24 genotypes of sunflower, sown by hand in randomized blocks with 4 replications. The rate of disease progress and the area under the disease progress curve (AUDPC) were calculated based on the severity of the disease in the lower, middle and upper thirds of the plants. The more resistant cultivars were PARDISE 33 followed by HLE 16, HLE 17, EXP 1452 CL, V 20041 and SRM 840.

KEY WORDS: Leaf spot, genetic resistance, Helianthus annuus.

A cultura do girassol (Helianthus annus L.) vem ganhando importância no Brasil, na inserção em sistemas de rotação e sucessão de culturas, apresentandoalta adaptabilidade em diferentes condições ambientais e oferecendo potencialidades de uso como biocombustível, alimentação humana e alimentação animal (THOMAZ, 2008).

Ofator doenças é bastante limitante para esta cultura. A planta é hospedeira de mais de 36 patógenos, a maioria fungos, que podem reduzir significativamente a produção e a qualidade de seus produtos (Zimmer; Hoes, 1978; Gulya et al., 1997).

O fungo Septoria helianthi foi originalmente relatado nos Estados Unidos da América, em 1924, (Henry; Gilbert, 1925) e, posteriormente, na Índia e Paquistão (HAmid; JALALUdDIN, 2007). No Estado do Rio Grande do Sul, recentemente foi relatada sua ocorrência causando manchas foliares e danos consideráveis ao girassol (Lenz et al., 2009). Como sintomas, observam-se manchas marrom-escuras, de formato irregular, com pequeno halo amarelado e diâmetro variando entre 10 e $18 \mathrm{~mm}$, que, com o avanço da doença, coalescem, principalmente a partir das margens das folhas.

Dentre as práticas de manejo de doenças de plantas, a utilização da resistência genética é uma estratégia de grande importância, visto queapresenta reduzido impacto ambiental, baixo custo e limitada necessidade de adoção de insumos (Costa et al., 2009). A identificação de genótipos que exibam maior nível de resistência a S. helianthi torna-se importante por se tratar de um fungo recentemente observado em condições naturais no Rio Grande do Sul. Este trabalho, portanto, teve por objetivo avaliar a reação de germoplasma de girassol a S. helianthi, para selecionar genótipos mais resistentes.

${ }^{2}$ Embrapa Clima Temperado, Pelotas, RS, Brasil. 
Foi avaliada a reação de 24 genótipos de girassol ao fungo $S$. helianthi em um experimento conduzido em campo, na área experimental do Departamento de Defesa Fitossanitária da Universidade Federal de Santa Maria, RS. Os tratamentos foram: M 734 (T); AGROBEL 960 (T); HELIO 358 (T); NTO 3.0; SRM 840; AROMO 10; SAUCE 1; PARAÍSO 22; PARAÍSO 20; PARAÍSO 33; ALBISOL 2; ALBISOL 20 CL; HLE 14; HLT 5013; EMBRAPA 01; HLT 5014; EXP 1450 HO; EXP 1452 CL; HLE 16; HLE 17; V 50070; V 70003 e V 20041.

A semeadura foi realizada manualmente no dia 26/9/2008, sendo a emergência ocorrida doze dias após. As parcelas mediam 2,80 × 6,00 m, com espaçamento entre linhas de $0,70 \mathrm{~m}$, sob delineamento de blocos ao acaso com quatro repetições. Os demais tratos culturais foram baseados nas indicações de cultivo de girassol no Rio Grande do Sul (LeITE et al., 2007).

A infecção ocorreu de forma natural, sendo que os primeiros sintomas foram observados em média aos 40 dias após emergência (DAE), no estádio V10 - V13, quando as plantas apresentavam de dez a treze folhas com mais de $4 \mathrm{~cm}$, segundo escala proposta por SCHNEITER; Miller (1981). A partir do aparecimento dos sintomas foram realizadas quatro avaliações de severidade da mancha de Septoria nos estádios descritos na Tabela 1. Utilizou-se um intervalo para descrever os estádios, com a finalidade de relatar a variação entre os genótipos, na mesma data de avaliação.

As plantas foram avaliadas considerando o terço inferior, médio e superior, sendo que para cada terço foram marcadas, com linha de algodão, dez folhas para que nas avaliações seguintes fossem consideradas sempre as mesmas folhas. Foram avaliadas cinco plantas por parcela localizadas nas duas linhas centrais da parcela, sendo desconsideradas as linhas de bordadura. Para determinação do percentual de área com sintomas da doença, foi utilizada a escala diagramática proposta por LENZ et al. (2009) que apresenta os níveis de 2, 12, 26, 48 e 71\% de tecido afetado.

A partir dos dados de severidade, calculou-se a área abaixo da curva de progresso da doença (AACPD) (CAMPBELL; MADDEN, 1990), baseado na fórmula: AACPD $=\Sigma\left(y_{i}+y_{i+1}\right) / 2 *\left(t_{i+1}-t_{i}\right)$, onde: $n$ = número de avaliações; $\mathrm{y}=$ severidade de septoria helianti (\%); t = tempo (dias). Também foi calculada a taxa de progresso da doença ( $\mathrm{r}$ ) (CAMPBELL; MADDEN, 1990), baseado na fórmula: $r=(1 / t)^{*} \ln \left(X / x_{0}\right)$, onde: $t=$ tempo decorrente entre a primeira e última avaliação (dias); $\ln =$ logarítmo natural; $X=$ severidade da doença na última avaliação $(\%) ; \mathrm{x}_{0}=$ severidade da doença na primeira avaliação (\%). A taxa de progresso da doença não foi calculada para o terço superior devido à pequena severidade. Os valores de AACPD foram submetidos à análise de variância e as médias comparadas através do teste de Tukey a 5\% de probabilidade de erro, com a utilização do programa PlotIT, versão3.2 para ambienteWindows.

A reação dos 24 genótipos a $S$. helianthi mostrou ampla variação (Tabela 2), não sendo verificada severidade significativa de outras doenças. De maneira geral, folhas inferiores foram as primeiras a apresentarem lesões e a AACPD foi mais alta nesse estrato, ao contrário das folhas superiores que apresentaram pequenos níveis de AACPD. Nas folhas do terço médio, a AACPD variou de 1,3 a 9,6\% em relação aos valores observados nas folhas inferiores, evidenciando diferenças quanto à reação dos genótipos ao avanço da doença da base para o ápice.

O genótipo que apresentou maior AACPD foi AROMO10, sendo também um dos primeiros a apresentar sintomas em campo. A taxa de progresso da doença para esse material foi alta no início da infecção (Tabela 3), alcançando valores de severidade de até $85 \%$ na segunda avaliação, o que contribuiu para que, aos 21 dias após o aparecimento dos primeiros sintomas, fosse observada queda prematura defolhas do terço inferior, correspondendo a uma severidade de 100\%. Entretanto, esse genótipo mostrou-se menos suscetível ao avanço da doença para os terços superiores, não apresentando sintomas nas folhas superiores. Seguidos de AROMO 10, os genótipos SAUCE 1 e HÉLIO 358 (T) também apresentaram altos valores de AACPD.

A cultivar que apresentou menor AACPD foi PARAÍSO 33, com valor aproximadamente $70 \%$ inferior à AROMO 10. Ao contrário do genótipo mais suscetível, PARAÍSO 33 foi um dos poucos que apresentou comportamento da taxa de progresso sempre crescente, gerando dados de severidade menores de $15 \%$ até os 21 dias após observação de sintomas (terceira avaliação) destacando-se também por não apresentar sintomas nas folhas superiores.

Tabela 1 - Estádios fenológicos da cultura do girassol ${ }^{1}$ em que foram realizadas as avaliações de severidade da mancha de Septoria e o tempo transcorrido entre a emergência e a avaliação. Santa Maria, 2008.

\begin{tabular}{lcc}
\hline Estádios & Descrição $^{2}$ & Dias após emergência \\
\hline V11 - V14 & Plantas com 11 a 14 folhas com mais de $4 \mathrm{~cm}$ & 45 \\
V13 - V16 & Plantas com 13 a 16 folhas com mais de $4 \mathrm{~cm}$ & 52 \\
V15 - V18 & Plantas com 15 a 18 folhas com mais de 4 cm & 59 \\
R1 & Aparecimento do broto floral & 66 \\
\hline
\end{tabular}

${ }^{1}$ De acordo com SCHNEITER; MiLLER (1981).

${ }^{2}$ Variação no número de folhas entre os genótipos trabalhados. 
Tabela 2 - Reação de genótipos de girassol ao fungo Septoria helianthi, avaliados pela área abaixo da curva de progresso da doença (AACPD) nos terços inferior, médio e superior, Santa Maria, 2008.

\begin{tabular}{|c|c|c|c|c|c|}
\hline \multirow{2}{*}{ Tratamento } & \multicolumn{3}{|c|}{$\mathrm{AACPD}^{1,2}$} & \multirow{2}{*}{ AACPD Total } & \multirow{2}{*}{ Média } \\
\hline & Terço inferior & Terço médio & Terço superior & & \\
\hline PARAÍSO 33 & $466,90 \mathrm{f}$ & $16,65 \mathrm{f}$ & $0,00 \mathrm{~d}$ & 483,55 & 161,18 \\
\hline HLE 16 & $665,96 \mathrm{e}$ & $13,83 \mathrm{f}$ & $0,10 \mathrm{~d}$ & 679,89 & 226,63 \\
\hline HLE 17 & $699,48 \mathrm{e}$ & $15,00 \mathrm{f}$ & $0,20 \mathrm{c}$ & 714,68 & 238,23 \\
\hline EXP 1452 CL & 710,15 e & $29,68 \mathrm{e}$ & $0,98 \mathrm{a}$ & 740,81 & 246,94 \\
\hline V 20041 & $728,88 \mathrm{e}$ & $19,80 \mathrm{f}$ & $0,20 \mathrm{c}$ & 748,88 & 249,63 \\
\hline SRM 840 & $766,15 \mathrm{e}$ & $53,50 \mathrm{c}$ & $0,10 \mathrm{~d}$ & 819,75 & 273,25 \\
\hline AGROBEL 960 (T) & $801,15 \mathrm{~d}$ & $43,78 \mathrm{~d}$ & $0,00 \mathrm{~d}$ & 844,93 & 281,64 \\
\hline NLT 5014 & $849,36 \mathrm{~d}$ & $29,60 \mathrm{e}$ & $0,10 \mathrm{~d}$ & 879,06 & 293,02 \\
\hline V 50070 & $854,53 \mathrm{~d}$ & $19,25 \mathrm{f}$ & $0,40 \mathrm{c}$ & 874,18 & 291,39 \\
\hline EMBRAPA 01 & $909,74 \mathrm{~d}$ & $64,43 \mathrm{~b}$ & $0,30 \mathrm{c}$ & 974,47 & 324,82 \\
\hline PARAÍSO 20 & $933,28 d$ & $34,75 \mathrm{e}$ & $0,88 \mathrm{a}$ & 968,91 & 322,97 \\
\hline ALBISOL 20 CL & $947,54 \mathrm{~d}$ & $91,20 \mathrm{a}$ & $0,00 \mathrm{~d}$ & 1038,74 & 346,25 \\
\hline ALBISOL 2 & $980,18 \mathrm{c}$ & $38,55 \mathrm{e}$ & $0,40 \mathrm{c}$ & 1019,13 & 339,71 \\
\hline HLE 14 & $1015,35 \mathrm{c}$ & $42,98 \mathrm{~d}$ & $0,30 \mathrm{c}$ & 1058,63 & 352,88 \\
\hline NTO 3.0 & $1028,04 \mathrm{c}$ & $45,00 \mathrm{~d}$ & $0,40 \mathrm{c}$ & 1073,44 & 357,81 \\
\hline V 70003 & 1044,05 c & $31,53 \mathrm{e}$ & $0,40 \mathrm{c}$ & 1075,98 & 358,66 \\
\hline HLT 5013 & $1051,23 \mathrm{c}$ & $14,38 \mathrm{f}$ & $0,40 \mathrm{c}$ & 1066,01 & 355,34 \\
\hline PARAÍSO 22 & $1054,73 \mathrm{c}$ & $22,70 \mathrm{f}$ & $0,20 \mathrm{c}$ & 1077,63 & 359,21 \\
\hline EXP $1450 \mathrm{HO}$ & $1109,33 \mathrm{c}$ & $21,28 \mathrm{f}$ & $0,00 \mathrm{~d}$ & 1130,61 & 376,87 \\
\hline M $734(\mathrm{~T})$ & $1136,28 \mathrm{c}$ & $47,28 \mathrm{~d}$ & $0,58 \mathrm{~b}$ & 1184,14 & 394,71 \\
\hline HLT 5009 & $1165,59 \mathrm{c}$ & $20,50 \mathrm{f}$ & $0,00 \mathrm{~d}$ & 1186,09 & 395,36 \\
\hline HELIO 358 (T) & $1261,75 \mathrm{~b}$ & $16,85 \mathrm{f}$ & $0,10 \mathrm{~d}$ & 1278,70 & 426,23 \\
\hline SAUCE 1 & $1344,88 \mathrm{~b}$ & $34,25 \mathrm{e}$ & $0,30 \mathrm{c}$ & 1379,43 & 459,81 \\
\hline AROMO 10 & 1488,11 a & $29,28 \mathrm{e}$ & $0,00 \mathrm{~d}$ & 1517,39 & 505,80 \\
\hline CV (\%) & 10,03 & 14,81 & 10,58 & - & - \\
\hline
\end{tabular}

${ }^{1}$ Área abaixo da curva de progresso da doença no intervalo de 45 a 66 dias após a emergência, correspondendo aos estádios V11-V14 até R1 descritos na tabela1.

${ }^{2}$ Médias seguidas por letras distintas diferem entre si ao nível de 5\% pelo teste de Scott-Knott.

BLOCK (2005) relatou que a natureza genética e a herança da resistência a S. helian thi ainda não sãoconhecidas. $\mathrm{O}$ autor afirma, ainda, que materiais selvagens de $H$. annuus, encontrados em diversas regiões dos Estados Unidos da América, foram avaliados e foram frequentemente observadas fontes de resistência nestes materiais. Fontes de resistência entre linhas puras também foram relatadas por CARSON (1985) e (1987).

Os genótipos HLE 16, HLE 17, EXP 1452 CL, V 20041 e SRM 840 apresentaram AACPD próximos ao do cultivar PARAÍSO 33 mais resistente, porém, o comportamento da taxa de progresso foi semelhante ao da grande maioria, com intervalo inicial decrescente e posteriormente crescente. Esse grupoé importante porque pode conter genes potencialmente úteis para o melhoramento da cultura do girassol para resistência a esta doença, assim como os encontrados em materiais selvagens desta espécie (BLOCK, 2005).

Entre os extremos de severidade, foi observado um grande grupo de cultivares com dados intermediários de AACPD e com a taxa de progresso obedecendo à tendência inicialmente decrescente e logo após crescente, no primeiro e segundo inter- valos, respectivamente. Exceções foram observadas para os cultivares PARAÍSO 20 e EMBRAPA 01, que tiveram comportamento inverso, sendo primeiro crescente e logo após decrescente.

Para os dados de AACPD dos terços médio e superior, não foi observada correlação, comparando-os aos dados obtidos no terço inferior. Ressalta-se ainda que o valor da AACPD observado no terço médio chegou a um máximo de $9,6 \%$ do valor observado no inferior. No terço superior não foi possível obter a relação com os demais estratos das plantas em estudo em função de a AACPD ter se apresentado pequena, sendo que, em alguns genótipos, não foi observada doença neste terço.

Tal fato mostraqueaascensão da doença em direção ao ápice da planta é pouco eficiente. Para isso, podem serconsideradosalgunsfatoresqueexerceminfluência na menor taxa de infecção das folhas dos terços médio e superior como maior interceptação de luz, menor umidade retida, maior atividade fotossintética e, com isso, o desencadeamento de rotas metabólicas importantes nas reações de defesa e, provavelmente, maior capacidadedeste patógenoeminfectarfolhas maduras. 
Tabela 3 - Taxa de progresso da mancha de septoria avaliada nos terços inferior e médio para os 24 genótipos de girassol trabalhados, Santa Maria, 2008.

\begin{tabular}{|c|c|c|c|c|c|c|}
\hline \multirow{2}{*}{ Cultivar } & \multicolumn{3}{|c|}{ Terço inferior } & \multicolumn{3}{|c|}{ Terço médio } \\
\hline & $\mathrm{r} 1$ & r2 & r3 & r1 & r2 & r3 \\
\hline M $734(\mathrm{~T})$ & 0,34 & 0,09 & 0,05 & 0,00 & 0,02 & 0,57 \\
\hline AGROBEL 960 (T) & 0,29 & 0,18 & 0,13 & 0,00 & 0,07 & 0,46 \\
\hline HELIO $358(\mathrm{~T})$ & 0,39 & 0,05 & 0,04 & 0,01 & 0,09 & 0,32 \\
\hline NTO 3.0 & 0,29 & 0,11 & 0,06 & 0,06 & 0,03 & 0,44 \\
\hline SRM 840 & 0,42 & 0,03 & 0,17 & 0,00 & 0,05 & 0,36 \\
\hline AROMO 10 & 0,60 & 0,04 & 0,02 & 0,02 & 0,07 & 0,38 \\
\hline SAUCE 1 & 0,61 & 0,08 & 0,02 & 0,01 & 0,11 & 0,33 \\
\hline PARAÍSO 22 & 0,48 & 0,03 & 0,12 & 0,03 & 0,13 & 0,03 \\
\hline PARAÍSO 20 & 0,32 & 0,16 & 0,07 & 0,08 & 0,14 & 0,11 \\
\hline PARAÍSO 33 & 0,13 & 0,16 & 0,32 & 0,00 & 0,07 & 0,25 \\
\hline ALBISOL 2 & 0,44 & 0,06 & 0,09 & 0,00 & 0,02 & 0,30 \\
\hline ALBISOL $20 \mathrm{CL}$ & 0,54 & 0,06 & 0,10 & 0,10 & 0,06 & 0,30 \\
\hline HLE 14 & 0,48 & 0,00 & 0,11 & 0,01 & 0,00 & 0,35 \\
\hline HLT 5009 & 0,68 & 0,08 & 0,04 & 0,09 & 0,04 & 0,20 \\
\hline HLT 5013 & 0,59 & 0,03 & 0,09 & 0,00 & 0,02 & 0,21 \\
\hline EMBRAPA 01 & 0,23 & 0,14 & 0,09 & 0,01 & 0,00 & 0,51 \\
\hline NLT 5014 & 0,48 & 0,07 & 0,12 & 0,04 & 0,12 & 0,11 \\
\hline EXP $1450 \mathrm{HO}$ & 0,49 & 0,07 & 0,06 & 0,01 & 0,04 & 0,20 \\
\hline EXP 1452 CL & 0,48 & 0,10 & 0,16 & 0,06 & 0,06 & 0,33 \\
\hline HLE 16 & 0,51 & 0,10 & 0,17 & 0,03 & 0,02 & 0,06 \\
\hline HLE 17 & 0,46 & 0,12 & 0,15 & 0,11 & 0,04 & 0,23 \\
\hline V 50070 & 0,50 & 0,08 & 0,12 & 0,01 & 0,03 & 0,30 \\
\hline V 70003 & 0,18 & 0,05 & 0,08 & 0,07 & 0,02 & 0,37 \\
\hline V 20041 & 0,22 & 0,10 & 0,15 & 0,03 & 0,00 & 0,21 \\
\hline
\end{tabular}

r1 - taxa de progresso da doença entre a primeira e a segunda avaliação (45-52 dias) correspondendo os estádios V11V14 a V13-V16.

r2 - taxa de progresso da doença entre a segunda e a terceira avaliação (52-59 dias) correspondendo os estádios V13-V16 a V15-V18.

r3 - taxa de progresso da doença entre a terceira e a quarta avaliação (59-66 dias) correspondendo os estádios V15-V18 a R1.
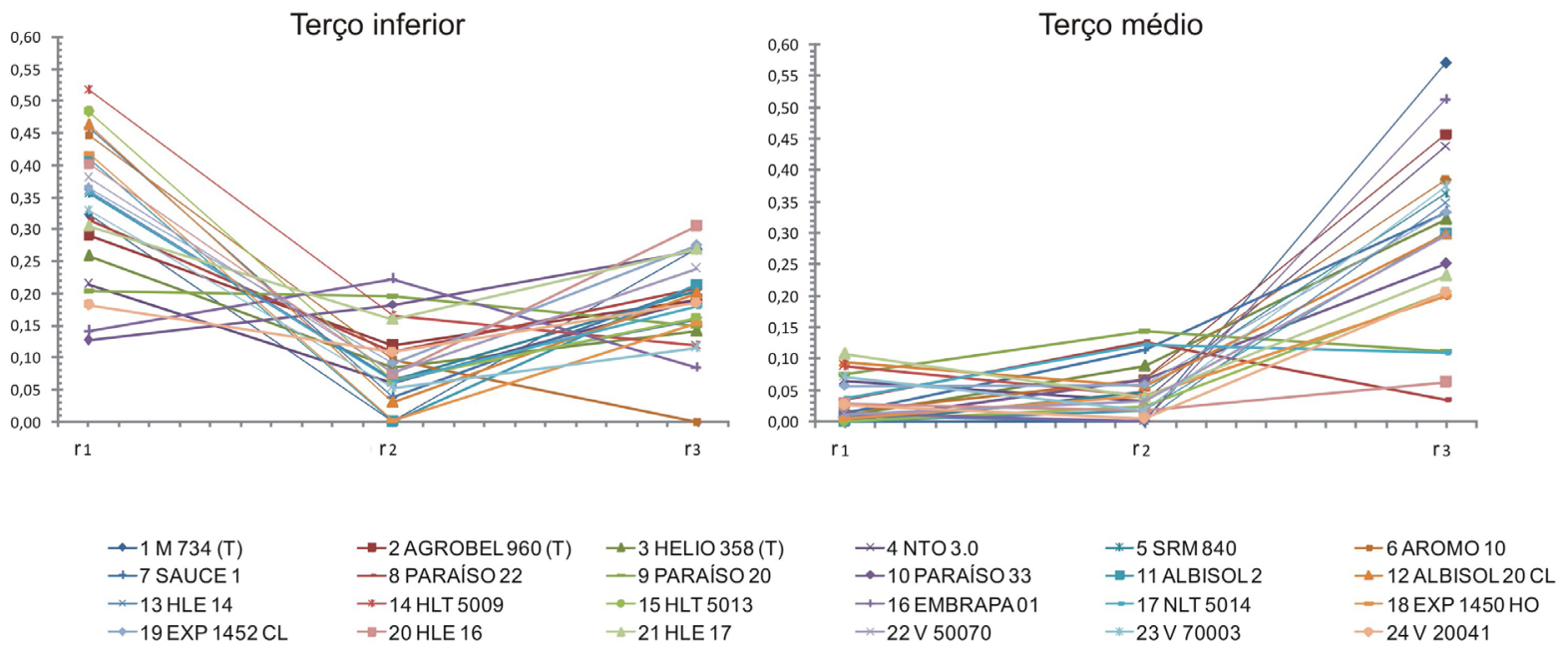

Fig. 1 - Dados de umidade relativa do ar $(\%)$ e temperatura $\left({ }^{\circ} \mathrm{C}\right)$ durante o ciclo dos diferentes genótipos de girassol, Santa Maria, 2008. 
Analisando a curva da taxa de progresso da doença em folhas inferiores e do terço médio é possível observar que houve um comportamento diferenciado entre estes dois segmentos (Fig. 1). No terço inferior, a taxa de progresso para a grande maioria dos genótipos avaliados foi alta, logo no início da infecção (r1), ou seja, foram observados altos valores de severidade já na segunda avaliação. No período seguinte (r2), é observado um declínio da taxa de progresso, que pode ter sido influenciado por condições adversas de clima, como pode ser observado na Figura 1, ou por uma fase do ciclo da cultura de maior reação ao patógeno, pois coincide com um estádio que apresenta grande expansão da área foliar sadia (V15 - V18). No terceiro período estudado, foi observada nova ascensão da taxa de progresso (r3), que culminou com o início dos estádios reprodutivos (R1) do ciclo da cultura, com maior porcentagem de tecido foliar maduro e menor atividades de defesa.

RADONS (2008) avaliando a relação severidade de mancha de septória com a produtividade de girassol irrigado, observou que o aumento mais acentuado de severidade da doença ocorreu dos 40 aos 50 DAE, durante e após um período de valores altos de umidade relativa do ar e, consequentemente, maior período de molhamento foliar, e que, após esse período, a doença evoluiu em uma menor taxa, devido a menor umidade.

No terço médio, a curva apresentou comportamento bastante variável de r1 para r2, dividido entre genótipos com taxa crescente e decrescentes. Porém, de r2 para r3, a grande maioria dos genótipos apresentou significativoacréscimo, podendoesta resposta também ser explicada pelo estágio avançado do ciclo da cultura, assim como no terço inferior.

Os resultados permitem constatar que os cultivares mais resistentes, isto é, que apresentaram menor AACPD são PARAÍSO 33, seguido por HLE 16, HLE 17, EXP 1452 CL, V 20041 e SRM 840. Quanto às que mostraram maior suscetibilidade à mancha de septória, recomenda-se especial ênfase na associação com programas de controle, principalmente naqueles locais onde existe histórico de ocorrência de infecção por $S$. helianthi, é o caso dos cultivares AROMO 10, SAUCE 1 e HÉLIO 358 (T). Sendo este um dos primeiros estudos relacionados à resistência de genótipos locais de girassol à mancha de septória, considera-se que mais estudos se fazem necessários, por tratar-se de uma doença recentemente observada e que apresenta potencial de danos à cultura.

\section{REFERÊNCIAS}

BLOCK, C.C. Evaluation of wild Helianthus annuus for resistance to Septoria leaf blight. Mandan: National Sunflower Association, 2005. 6p. Disponível em: <http://www.sunflowernsa.com/uploads/research/211/ Block_Septoria_05.PDF>. Acesso em: 16 fev. 2010.

CAMPBELL, C.L.; MADDEN, L.V. (Ed.). Introduction to plant disease epidemiology. New York, NY: Wiley, 1990. 532p.

CARSON, M.L. Reactions of sunflower inbred lines to two foliar pathogens. Plant Disease, v.69, n.1, p.986-988, 1985.

CARSON, M.L. Effects of two foliar pathogens on seed of sunflower. Plant Disease, v.71, n.1, p.549-551, 1987.

COSTA, I.F.D.; BALARDIN, R.S.; MEDEIROS, L.A.M.; LENZ, G.; GULART, C.A.; ZEMOLIN, C.R.; SILVA, T.M.B. Reação de germoplasma comercial de soja a Colletotrichum truncatum. Tropical Plant Pathology, v.34, n.1, p.47-50, 2009.

GULYA, T.J.; RASHID, K.Y.; MASIREVIC, S.M. Sunflower diseases. In: SCHNEITER, A.A. (Ed.). Sunflower technology and production. Madison: American Society of Agronomy, 1997. p.263-379.

HAMID, M.; JALALUDDIN, M. A new report of Septoria helianthi leaf spot of sunflower from Sindh. Pakistan Journal of Botany, v.39, n.2, p.659-660, 2007.

HENRY, A.W.; GILBERT, H.C. Important diseases of the common sunflower. Minnesota Studies in Plant Science, v.5, n.1, p.285, 1925.

LEITE, R.M.V.B. de C.; CASTRO, C.; BRIGHENTI, A.M.; OLIVEIRA, A.O.; CARVALHO, C.G.; OLIVEIRA, A.C.B. Indicações para o cultivo do girassol nos Estados do Rio Grande do Sul, Paraná, Mato Grosso do Sul, Mato Grosso, Goiás e Roraima. Londrina: Embrapa Soja, 2007. (Comunicado Técnico, n.78).

LENZ, G.; COSTA, I.F.D.; BALARDIN, R.S.; STEFANELO, M.S.; MARQUES, L.N.; MELO, A.A. Escala diagramática para avaliação de severidade de mancha-de-septoria em girassol. Ciência Rural, v.39, n.8, p.2527-2530, 2009.

RADONS, S.Z. Severidade de ocorrência de mancha de septória e produtividade do girassol irrigado. 2008. 67f. Dissertação (Mestrado) - Universidade Federal de Santa Maria, Santa Maria, 2008.

SCHNEITER, A.A.; MILLER, J.F. Description of sunflower growth stages. Crop Science, v.21, n.1, p.901-903, 1981.

THOMAZ, G.L. Comportamento de cultivares de girassol em função da época de semeadura na região de Ponta Grossa, PR. 2008. 92f. Dissertação (Mestrado) - Universidade Estadual de Ponta Grossa, Ponta Grossa, 2008.

ZIMMER, D.E.; HOES, J.A. Diseases. In: CARTER, J.F. (Ed.). Sunflower science and technology. Madison: American Society of Agronomy, 1978. p.225-262.

Recebido em 23/2/10

Aceito em 3/2/11 